\title{
RESULTS OF SURGICAL TREATMENT OF NON-SMALL CELL LUNG CANCER: VALIDATION OF THE NEW POSTOPERATIVE PATHOLOGIC TNM CLASSIFICATION
}

Jacek Jassem, MD

Jan Skokowski, MD ${ }^{\mathrm{b}}$

Rafał Dziadziuszko, MD

Ewa Jassem, MD

Amelia Szymanowska, BSc ${ }^{c}$

Witold Rzyman, MD ${ }^{\mathrm{b}}$

Andrzej Roszkiewicz, $\mathrm{MD}^{\mathrm{d}}$
Objective: Prognostic relevance of the current TNM stage grouping for lung cancer is still a matter of debate.

Methods: To validate the new pathologic TNM classification for non-small cell lung cancer, we analyzed the survival data of 586 patients who underwent complete pulmonary resection and pathologic staging at one institution.

Results: The current TNM stage grouping well reflected the long-term prognostic hierarchy. There was a good distinction between new substages IA and IB (5-year survivals of $66 \%$ and $53 \%$, respectively). The subdivision of stage II led to an under-representation of stage IIA (6 patients [1.0\%]), and therefore the appropriateness of this modification could not be verified. Fiveyear survival in the T3 N0 category (30\%) was significantly better than that found in the new stage IIIA (15\%). No difference was found between T3 N0 and $\mathrm{T} 2 \mathrm{~N} 1$, the categories constituting new stage IIB. Within stage IIIA there was a significant survival difference between T3 N2 (6\%) and the remaining $\mathrm{T}$ and $\mathrm{N}$ designations (18\%). Moreover, the 5-year survival in the T3 N1 category $(35 \%)$ was similar to that found in the new stage IIB $(27 \%)$ and better than in any $\mathrm{T}$ N2 tumors $(12 \%)$.

Conclusion: Most of our findings confirmed prognostic relevance of the current pTNM stage grouping in patients with resectable non-small cell lung cancer. However, despite recent modifications, there is still a significant heterogeneity that flaws stage IIIA. (J Thorac Cardiovasc Surg 2000;119:1141-6)
A precise staging system is of paramount value for selecting therapeutic strategy, estimating prognosis, and evaluating treatment results in cancer. In non-small cell lung cancer (NSCLC) the tumor stage is defined by using the International Union Against Cancer/American Joint Commission (UICC/AJC) TNM classification. Since its introduction in the late 1950s, the TNM classification has undergone several refinements to prognostically select most homogeneous groups. Its last revision was done in $1997 .^{1}$ Major modifications in NSCLC staging included subdivision of stages I and II

From the Departments of Oncology and Radiotherapy, ${ }^{\mathrm{a}}$ Thoracic Surgery, ${ }^{\mathrm{b}}$ Pneumonology, ${ }^{\mathrm{c}}$ and Pathology, ${ }^{\mathrm{d}}$ Medical University of Gdansk, Poland.

Received for publication July 21, 1999; revisions requested Sept 22, 1999; revisions received Jan 17, 2000; accepted for publication Jan 18, 2000.

Address for reprints: Jacek Jassem, MD, Department of Oncology and Radiotherapy, Medical University of Gdansk, 7 Dębinki St, 80-211 Gdańsk, Poland (E-mail: jjassem@amedec.amg.gda.pl).

Copyright () 2000 by The American Association for Thoracic Surgery

0022-5223/2000 $\$ 12.00+0 \quad \mathbf{1 2 / 1 / 1 0 5 8 2 5}$

doi:10.1067/mtc.2000.105825 into $\mathrm{A}$ and $\mathrm{B}$ categories and the assignment of T3 N0 M0 tumors to stage IIB. Although these changes emerged from analysis of a large retrospective database, the question of whether they reflect the prognosis more precisely is still a matter of debate. ${ }^{2,3}$ Thus, a validation of the new stage grouping by means of retrospective analysis of a large series of patients has been repeatedly postulated.

In the present study we conducted the evaluation of prognostic value of the current pathologic TNM classification $^{4}$ in a group of 586 patients who underwent complete resection of NSCLC in one institution.

\section{Patients and methods}

During the period between January 1, 1991, and June 30, 1995, 698 patients with primary lung cancer underwent pulmonary resection for lung cancer at the Department of Thoracic Surgery, Medical University of Gdańsk, Poland. Excluded from further analysis were 41 patients with small cell lung cancer, 17 patients with undifferentiated or mucoepidermoid cancers, 26 patients with incomplete nodal dissection or undefined T stage, 13 patients who underwent palliative resection, and 15 patients with insufficient clinical data. The remaining 
Table I. Patient characteristics

\begin{tabular}{lc}
\hline & No. of patients (\%) \\
\hline Age (y) & \\
$31-40$ & $9(1.5)$ \\
$41-50$ & $85(15)$ \\
$51-60$ & $233(40)$ \\
$61-70$ & $228(39)$ \\
$71-80$ & $31(5.3)$ \\
Sex & \\
Male & $463(79)$ \\
Female & $123(21)$ \\
Histology & \\
Squamous cell carcinoma & $365(62)$ \\
Adenocarcinoma & $150(26)$ \\
Large cell carcinoma & $48(8.2)$ \\
NSCLC, other & $23(3.9)$ \\
Type of operation & \\
Pneumonectomy & $241(41)$ \\
Bilobectomy & $43(7.3)$ \\
Lobectomy & $258(44)$ \\
Lobectomy with sleeve resection & $28(4.8)$ \\
Segmentectomy & $16(2.8)$ \\
\hline
\end{tabular}

586 patients who met the criteria of this study were analyzed for their survival. Routine pretreatment staging within this period included chest radiography in two planes, examination with a fiberoptic bronchoscope, chest computed tomography, and abdominal ultrasonography or computed tomography. Mediastinoscopy was not routinely performed. Brain computed tomography and bone scintigraphy were done only in case of clinical suspicion of brain or bone involvement, respectively. In principle, postoperative irradiation was not administered; however, a few patients received radiotherapy according to individual decisions made by the treating physicians. Induction or adjuvant chemotherapy was not performed throughout the analyzed period. Operations included pulmonary resection (extent presented in Table I) with the systemic dissection of hilar and mediastinal lymph nodes. A Naruke map ${ }^{5}$ was used for lymph node classification. The pathologic examination of resected material served as the basis for the UICC/AJC pTNM classification of $1997 .{ }^{4}$ Histologic typing was determined according to the World Health Organization classification. ${ }^{6}$ Survival probability and its $95 \%$ confidence interval (CI) were computed by using the life-table method of Kaplan and Meier, with the date of the operation set as zero time. Postoperative 30-day deaths were included in the survival analysis. The Wilcoxon-Gehan and log-rank statistics were used for the univariate statistical comparisons of survival curves with a 95\% CI. The Cox proportional hazard model was used to calculate the hazard ratio and its 95\% CI for particular stage categories. Analysis was carried out with a software package (STATISTICA 5.0, StatSoft, Inc, Tulsa, Okla).

\section{Results}

Table I shows the major patient characteristics, and Table II shows the distribution of particular T, N, and $\mathrm{M}$ designations. Follow-up information was available for all patients. The median follow-up for the censored observations was 60 months. By the time of the final analysis (January 1999), 389 (66\%) of the 586 patients had died (uncensored observations), and 201 (34\%) were alive. A total of $487(83 \%)$ patients died or were followed up for at least 5 years. The median survival for the entire group was 29 months, and the 5-year survival was $36 \%$ (95\% CI, 34\%-38\%). Nineteen (3.2\%) patients died within 30 days after the operation. Postoperative 30-day mortality was related to the stage of disease; there were 7 (2.1\%) deaths in 341 patients with stage I-IIA disease and $12(4.9 \%)$ deaths in 245 patients with stage IIB-IV disease $(P=.06)$.

The current TNM stage grouping well reflected the long-term prognostic hierarchy (Table II and Fig 1). In the new system there was a good distinction between stage I subsets. Five-year survivals for stages IA and IB were $66 \%$ (95\% CI, 51\%-81\%) and 53\% (95\% CI, 46\%-60\%), respectively (IA vs IB: $P<.01$ and $P=.09$ for Wilcoxon and log-rank test, respectively). After the subdivision of stage II, stage IIA was represented by only $6(1.0 \%)$ patients; therefore, the appropriateness of this modification could not be verified. Five-year survival probability in the T3 N0 category $(30 \%[95 \%$ CI, 18\%-42\%]) was significantly higher than that found in the new stage IIIA (15\% [95\% CI, 9\%-21\%]; T3 N0 vs IIIA: $P=.03$ and $P=.02$ for Wilcoxon and log-rank test, respectively; Fig 2). No difference was found between T3 N0 (30\% [95\% CI, 18\%-42\%]) and T2 N1 (24\% [95\% CI, 13\%-35\%]), the categories constituting new stage IIB (T3 N0 vs T2 N1: $P=.73$ and $P=.96$ for Wilcoxon and log-rank test, respectively). Within stage IIIA, there was a significant 5-year survival difference between T3 N2 (6\% [95\% CI, 0\%$14 \%]$ ) and the remaining $\mathrm{T}$ and $\mathrm{N}$ designations (18\% [95\% CI, $11 \%-25 \%$ ]; T3 N2 vs other IIIA substages: $P$ $=.03$ and $P=.02$ for Wilcoxon and log-rank test, respectively; Fig 3). Moreover, the 5-year survival in the T3 N1 category (35\% [95\% CI, 16\%-53\%]) was similar to that found in the new stage IIB (27\% [95\% CI, $19 \%-35 \%$ ]; T3 N1 vs IIB: $P=.53$ and $P=.87$ with Wilcoxon and log-rank test, respectively). Five-year survival in T3 N1 tumors was better than that found in a subset of stage IIIA tumors with N2 disease (12\% [95\% CI, 6\%-17\%]; T3 N1 vs any T N2: $P=.17$ and $P$ $=.06$ with Wilcoxon and log-rank, respectively; Fig 3). There was a striking difference in 5-year survivals between clustered stage IIB and T3 N1 tumors (28\% [95\% CI, 21\%-36\%]) and the stage IIIA tumors with 

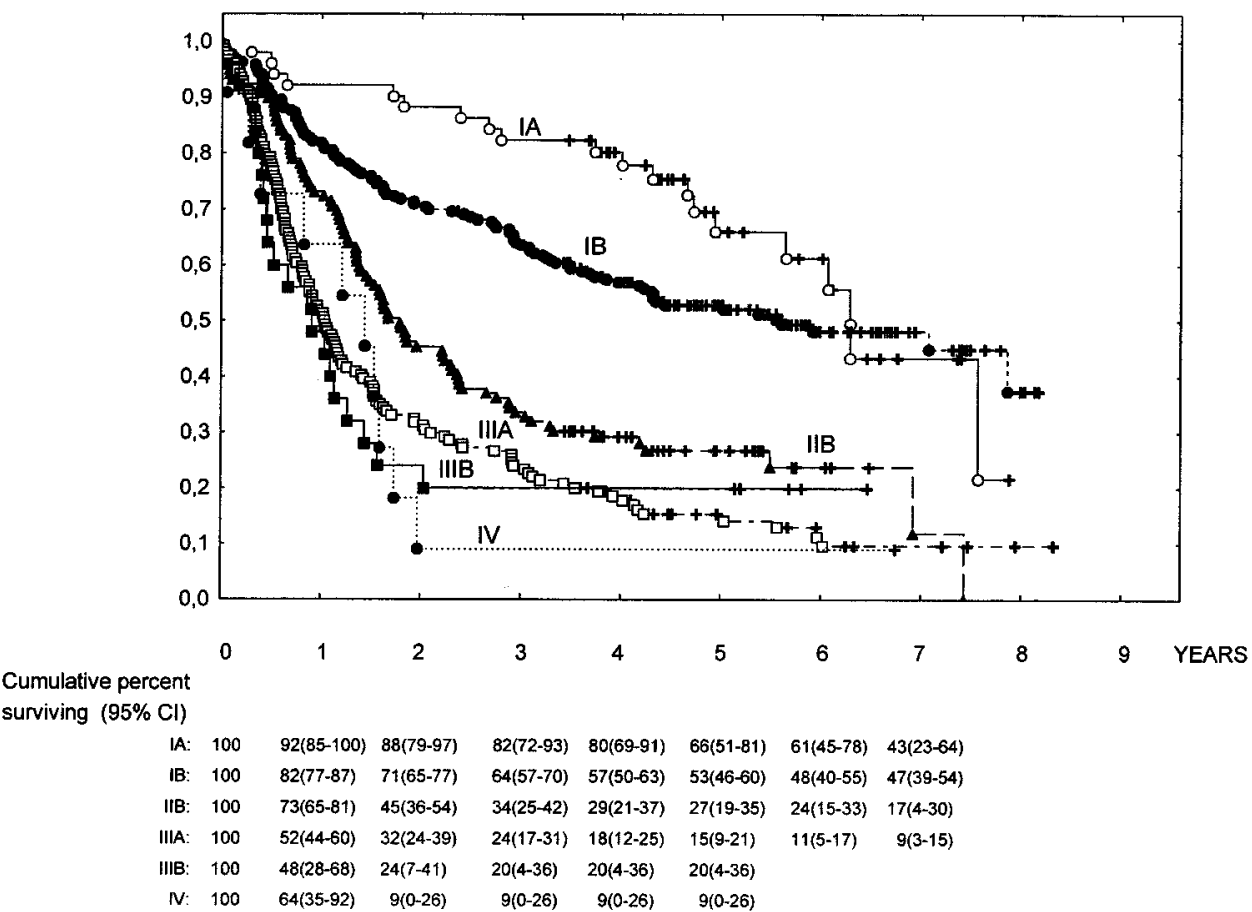

Fig 1. Probability of survival according to clinical stage. Stage IIA is not presented because of a limited number of patients.

Table II. Five-year survival according to pTNM categories and staging

\begin{tabular}{|c|c|c|c|c|c|}
\hline $\begin{array}{l}p T N M \\
\text { category }\end{array}$ & $\begin{array}{c}\text { No. of } \\
\text { patients (\%) }\end{array}$ & $\begin{array}{c}\text { No. of 5-year } \\
\text { survivors/ } \\
\text { 5-year survival } \\
(95 \% \text { CI) }\end{array}$ & $\begin{array}{c}\text { Pathologic } \\
\text { stage }\end{array}$ & $\begin{array}{l}\text { Five-year } \\
\text { survival } \\
(95 \% \text { CI })\end{array}$ & $\begin{array}{l}\text { Hazard } \\
\text { ratio } \\
(95 \% \text { CI })\end{array}$ \\
\hline T1 N0 M0 & $51(8.7)$ & $16 / 66 \%(51 \%-81 \%)$ & IA & $66 \%(51 \%-81 \%)$ & 1.0 \\
\hline T2 N0 M0 & $220(37.5)$ & $69 / 53 \%(46 \%-60 \%)$ & IB & $53 \%(46 \%-60 \%)$ & $1.5(0.9-2.4)$ \\
\hline T1 N1 M0 & $6(1.0)$ & $1 / 17 \%(0 \%-46 \%)$ & IIA & $17 \%(0 \%-46 \%)$ & Not able to be evaluated \\
\hline T2 N1 M0 & $64(10.9)$ & $7 / 24 \%(13 \%-35 \%)$ & & & \\
\hline T3 N0 M0 & $55(9.4)$ & $8 / 30 \%(18 \%-42 \%)\}$ & IIB & $27 \%(19 \%-35 \%)$ & $3.7(2.2-6.1)$ \\
\hline T1 N2 M0 & $11(1.9)$ & $2 / 18 \%(0 \%-41 \%)$ & \multirow{4}{*}{ IIIA } & \multirow{4}{*}{$15 \%(9 \%-21 \%)$} & \multirow{4}{*}{$4.7(2.9-7.6)$} \\
\hline $\mathrm{T} 2 \mathrm{~N} 2 \mathrm{M} 0$ & $84(14.3)$ & $5 / 13 \%(6 \%-21 \%)$ & & & \\
\hline T3 N1 M0 & $26(4.4)$ & $4 / 35 \%(16 \%-53 \%)$ & & & \\
\hline T3 N2 M0 & $33(5.6)$ & $2 / 6 \%(0 \%-14 \%)$ & & & \\
\hline T1-3 N3 M0 & $4(0.7)$ & $0 / 0 \%$ & \multirow{2}{*}{ IIIB } & \multirow{2}{*}{$20 \%(4 \%-36 \%)$} & \multirow{2}{*}{$4.7(2.4-8.9)$} \\
\hline T4 N0-2 M0 & $21(3.6)$ & $5 / 24 \%(16 \%-42 \%)\}$ & & & \\
\hline Any TN M1 & $11(1.9)$ & $1 / 9 \%(0 \%-26 \%)$ & IV & $9 \%(0 \%-26 \%)$ & $6.4(2.8-14.3)$ \\
\hline
\end{tabular}

mediastinal nodal involvement $(12 \%$ [95\% CI, 6\%$17 \%]$; IIB + T3 N1 vs any T N2: $P<.01$ and $P=.01$ for Wilcoxon and log-rank test, respectively).

\section{Discussion}

The aim of the present study was to assess the validity of the current pathologic TNM classification for operable NSCLC. We restricted our analysis to a peri- od from 1991-1995 because within this time the completeness of clinical data and pathologic staging could adequately be verified. The relatively long follow-up period allowed for relevant analysis of survival data. All patients were treated according to current surgical standards (ie, with pulmonary resection and dissection of the regional lymph nodes). The number of pneumonectomies, however, was higher compared with 


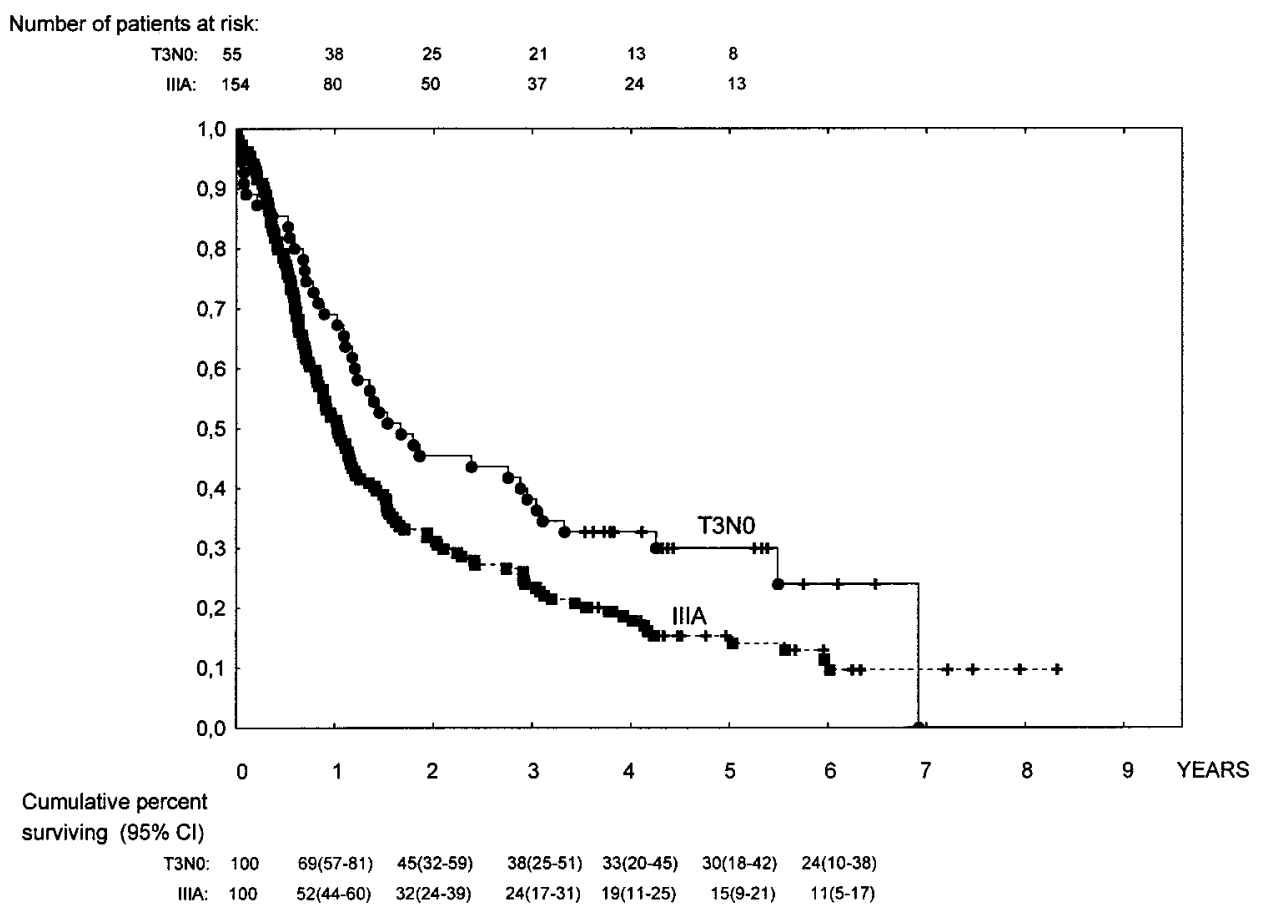

Fig 2. Probability of survival in the T3 N0 category $(\mathrm{n}=55)$ and stage IIIA $(\mathrm{n}=154$; T3 N0 vs IIIA: $P=.03$ and $P=.02$ for Wilcoxon and log-rank test, respectively).

numbers found in other modern series. This feature was most probably associated with the relatively high number of patients with stage III disease, usually requiring more radical approaches. Moreover, in contrast to many other series, the proportion of patients with adenocarcinoma, a tumor typically located in the periphery of the lung and managed with a less extensive operation, was relatively low.

The overall survival obtained in this series was within the range reported by other authors. ${ }^{1,7,8}$ However, the results in selected categories were somewhat lower than those found in some other surgical series. ${ }^{7,9,10}$ This variation may be related to the extent of pretreatment evaluation, as well as to the accuracy of nodal sampling and pathology reporting.

As expected, the current pTNM classification well reflected the prognosis in particular stages. The stage I subdivision was associated with more precise prediction of prognosis within the new substages. Significant distinction between these categories has been demonstrated in Mountain's collected database ${ }^{1}$ and in a number of individual studies (Table III).

As in other large surgical series, ${ }^{7-12}$ the division of stage II into A and B categories led to an under-representation of stage IIA (T1 N1). The proportion of this stage in our material was $1.0 \%$, and that found in other surgical series ranged between $0.5 \%$ and $4.4 \% .^{1,7-12}$ Because of the small number of patients with stage IIA disease, we could not verify the clinical relevance of the stage II subdivision. In the largest retrospective series with the new classification (5155 patients, with 1892 included in the pTNM analysis), the prognosis of stages IIA and IIB was of significant difference only in the clinical classification and not in the pathologic classification. ${ }^{11}$ However, a difference between these substages was detected in a cumulative series of 1910 surgical patients serving as the base for the current classification $^{1}$ and in the recently reported Japanese study of 1310 patients. $^{9}$ Nevertheless, the value of stage II subdivision is questionable. Because at least 4 large studies, including the cumulative series of Mountain, demonstrated no difference in survival between stages IB and IIA, ${ }^{1,7,9,11}$ their amalgamation into one stage might in the future be considered.

Similar to other studies, ${ }^{1,7,9}$ in our series prognosis of the T3 N0 category was significantly better than that of the reshuffled stage IIIA (5-year survivals of $30 \%$ and $15 \%$, respectively). At the same time, there was no significant difference in survival between patients with $\mathrm{T} 3$ N0 and T2 N1 disease. These results support the appropriateness of excluding T3 N0 disease from stage IIIA and its assignment to stage IIB. Because of the limited 


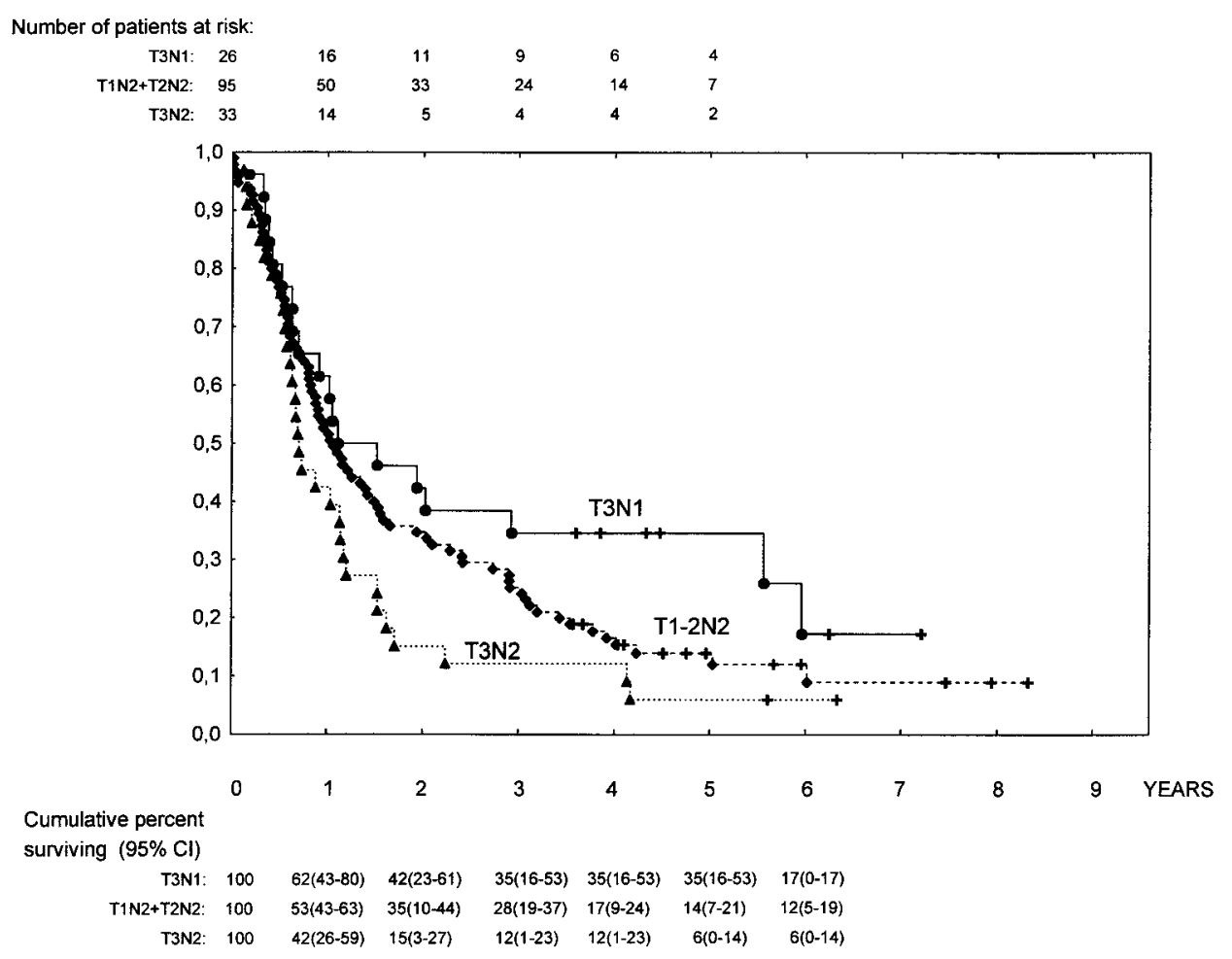

Fig 3. Probability of survival in stage IIIA subcategories: T3 N1 $(n=26)$, T1-2 N2 $(n=95)$, and T3 N2 $(n=33)$.

Table III. Relevance of new pTNM classification in large surgical series

\begin{tabular}{|c|c|c|c|c|c|}
\hline \multirow[b]{2}{*}{ Reference } & \multirow[b]{2}{*}{$\begin{array}{c}\text { No. of } \\
\text { patients }\end{array}$} & \multicolumn{3}{|c|}{ Relevance of new assignments ( $\mathrm{P}$ value) } & \multirow[b]{2}{*}{ Other findings } \\
\hline & & $\begin{array}{c}I A v s \\
I B\end{array}$ & $\begin{array}{l}I I A v s \\
I I B\end{array}$ & $\begin{array}{l}\text { T2 N1 MO } \\
\text { vs T3 NO MO }\end{array}$ & \\
\hline Mountain, ${ }^{1} 1997$ & $1910^{*}$ & $<.05$ & $<.05$ & $>.05$ & No difference between IB and IIA \\
\hline Drings and colleagues, ${ }^{11} 1997$ & 1892 & .001 & .114 & Not reported & No difference between IB and IIA \\
\hline Inoue and colleagues, ${ }^{9} 1998$ & 1310 & .001 & .02 & $>.05$ & $\begin{array}{l}\text { No difference between IB and IIA; } \\
\text { no difference between T3 N0 and T3 N1 }\end{array}$ \\
\hline Rami-Porta, ${ }^{8} 1998$ & $1749^{\dagger}$ & .0006 & .12 & Not reported & No difference between IB and IIA \\
\hline Present series & 586 & $<.01$ & Not able to be evaluated & .73 & No difference between $\mathrm{T} 3 \mathrm{~N} 0$ and $\mathrm{T} 3 \mathrm{~N} 1$ \\
\hline
\end{tabular}

"Collected database.

'Series included patients who underwent both curative resection and exploratory thoracotomy. Three-year survival is reported.

number of patients with T3 N0-1 tumors in the present series, no analysis was made in relation to involved structures (chest wall, main stem bronchus within $2 \mathrm{~cm}$ of the carina, diaphragm, mediastinal structures, and brachial plexus). It has previously been demonstrated that the $\mathrm{T} 3$ category is heterogeneous; tumors involving the chest wall carry a significantly better prognosis than those infiltrating the mediastinum, diaphragm, or main stem bronchus. ${ }^{9,13}$

Despite its recent refinement, a large heterogeneity was found within stage IIIA. The combination of a T3 lesion and involved mediastinal lymph nodes carried a particularly dismal prognosis, with virtually no patients experiencing prolonged survival. As in other surgical series, $7,9,10,13,14$ within stage IIIA, prognosis in the T3 $\mathrm{N} 2$ category was remarkably worse than that found in the remaining $\mathrm{T}$ and $\mathrm{N}$ designations. On the other hand, the prognosis in the T3 N1 category was better than that in any other IIIA disease and similar to that of T3 N0 tumors. A similar outcome has also been found in other large surgical series. $7,9,10,13-15$ Thus, T3 N1 disease seems to be another candidate to be incorporated 
into stage IIB, as already postulated before the last modification of the TNM system. ${ }^{15}$

Interestingly, in our series the outcome in IIIA disease was not much different from that found in stage IIIB disease. This finding, reported also in other surgical series, ${ }^{8,9}$ was probably a result of the small number of patients with stage IIIB disease. Most important, however, stage IIIB tumors are only exceptionally resectable, and therefore the analyzed group of patients was highly selective and not representative for this category; for example, only 4 of 25 patients had N3 disease, and 10 of 21 patients with T4 disease had N0-1 disease. The same reasons apply to a relatively good outcome in patients with stage IV disease.

In conclusion, most of our findings confirmed the relevance of the current pTNM classification in determining the clinical course of patients with resectable NSCLC. However, despite recent modifications, there is still a significant heterogeneity that flaws IIIA disease. Further refinements of this category should therefore be considered to place these patients within more homogeneous staging groups.

\section{REFERENCES}

1. Mountain CF. Revisions in the international system for staging lung cancer. Chest 1997;111:1710-7.

2. Ginsberg RJ. Continuing controversies in staging NSCLC: an analysis of the revised 1997 staging system. Oncology 1998;12(Suppl 2):51-4.

3. Leong SS, Rocha Lima CM, Sherman CA, Green MR. The 1997 international staging system for non-small cell lung cancer: Have all the issues been addressed? Chest 1999;115:242-8.
4. International Union Against Cancer. TNM classification of malignant tumors. 5th ed. New York: Wiley-Liss; 1997. p. 93-7.

5. Naruke T, Suemasu K, Ishikawa S. Lymph node mapping and curability of various levels of metastases in resected lung cancer. J Thorac Cardiovasc Surg 1978;76:832-9.

6. World Health Organization. Histological typing of lung tumors. 2nd ed. Geneva: World Health Organization; 1981.

7. Naruke T, Goya T, Tsuchiya R, Suemasu K. Prognosis and survival in resected lung carcinoma based on the international staging system [published erratum appears in J Thorac Cardiovasc Surg 1989;97:350]. J Thorac Cardiovasc Surg 1988;96:440-7.

8. Rami-Porta R. Reflections on the revisions in the international system for staging lung cancer. Chest 1998;113:1728-9.

9. Inoue K, Sato M, Fujimura S, Sakurada A, Takahashi S, Usuda K, et al. Prognostic assessment of 1310 patients with non-small cell lung cancer who underwent complete resection from 1980 to 1993. J Thorac Cardiovasc Surg 1998;116:407-11.

10. Ichinose Y, Yano T, Asoh H, Yokoyama H, Yoshino I, Katsuda Y. Prognostic factors obtained by a pathologic examination in completely resected non-small cell lung cancer: analysis in each pathologic stage. J Thorac Cardiovasc Surg 1995;110:601-5.

11. Drings P, Bülzebruck H, Vogt-Moykopf I. Prognostic impact of the new 5th edition of the TNM classification for lung cancer (1997) [abstract]. Lung Cancer 1997;18(Suppl 1):215.

12. Bülzebruck H, Bopp R, Drings P, Bauer E, Krysa S, Probst G, et al. New aspects in the staging of lung cancer: prospective validation of the International Union Against Cancer TNM classification. Cancer 1992;70:1102-10.

13. Detterbeck FC, Socinski MA. IIB or not IIB: the current question in staging non-small cell lung cancer. Chest 1997; 112:229-34.

14. Watanabe Y, Shimuzu J, Oda M, Hayashi Y, Watanabe S, Iwa T. Results of surgical treatment in patients with stage IIIA non-small cell lung cancer. Thorac Cardiovasc Surg 1991;39:44-9.

15. Green MR, Lilenbaum RC. Stage IIIA category of non-small cell lung cancer: a new proposal. J Natl Cancer Inst 1994;86:586-8.

\section{Availability of Journal back issues}

As a service to our subscribers, copies of back issues of The Journal of Thoracic and Cardiovascular Surgery for the preceding 5 years are maintained and are available for purchase from Mosby until inventory is depleted. The following quantity discounts are available: $25 \%$ off on quantities of 12 to 23, and one third off on quantities of 24 or more. Please write to Mosby, Subscription Customer Service, 6277 Sea Harbor Dr, Orlando, FL 32877, or call 800-654-2452 or 407-345-4000 for information on availability of particular issues and prices. If unavailable from the publisher, photocopies of complete issues may be purchased from Bell \& Howell Information and Learning, 300 N Zeeb Rd, Ann Arbor, MI 48106-1346; 734-761-4700 or 800-521-0600. 